\title{
Covid-19 Pandemisinde Hemşirelik Öğrencilerinin Ĕ̆itimi: Uzaktan Eğitim Süreci ve Etkileri
}

\author{
Funda KARAMAN*, Sultan ÇAKMAK ${ }^{* *}$, Ayşe Nur YEREBAKAN****
}

\section{$\ddot{0} \mathbf{z}$}

Amaç: Bu çalışmada, Covid-19 pandemi döneminde hemşirelik öğrencilerinin uzaktan eğitim süreci ve etkilerinin belirlenmesi amaçlanmıştır.

Yöntem: Tanımlayıcı olarak gerçekleştirilen araştırmanın örneklemini, bir üniversitenin Sağlık Bilimleri Fakültesi Hemşirelik Bölümünde öğrenim gören 243 öğrenci oluşturmuştur. Araştırmanın verileri "Tanıtıcı Bilgi Formu" ve "Uzaktan Eğitim Sürecine Yönelik Bilgi Formu" kullanılarak toplanmıştır. Verilerin analizinde tanımlayıcı istatistiksel metotlar kullanılmıștır.

Bulgular: Araştırmaya katılan öğrencilerin \%92.2'si hemşirelik bölümünü isteyerek tercih ettiklerini ifade etmişlerdir. Katılımcı öğrencilerin \%84.8'i uzaktan eğitim sürecinin uygulamalı hemşirelik eğitimini olumsuz etkilediğini, \%53.5’i de teorik hemşirelik eğitimini olumsuz etkilediğini belirtmiştir. Öğrencilerin \%68.7'si çevrimiçi dersin zaman kazandırdığını, böylece diğer birçok işini yapabildiğini ifade etmekle birlikte; \%81.5’i uygulamaya dayalı derslerin uzaktan verilmesinin yeterli olmadığını düşünmektedir. Teorik derslerin uzaktan verilmesinin yeterli olduğunu düşünenlerin oranı \%57.2 iken; öğrencilerin \%63.4'ünün uzaktan eğitim sisteminde derslerin verimliliği konusunda endişesi olduğu, çevrimiçi ders sırasında anlatılan ders içeriğinin tamamının anlaşılma oranının ise \%50.3 olduğu saptanmıştır. Öğrencilerin \%58’i çevrimiçi dersi nedeniyle göz sorunu, baş ağrısı gibi şikâyetler yaşadığını belirtmiştir.

Sonuç: Pandemi dönemindeki uzaktan eğitim hemşirelik öğrencileri tarafından zaman ve mekân esnekliği açısından büyük kolaylık olarak görülmüş olsa da; öğrencilerde öğrenme güçlüğü, uygulama ve klinik deneyimlerde adaptasyon zorluğu, hemşirelik becerilerinin gelişme sürecinin olumsuz etkilenmesi gibi sonuçlara neden olduğu saptanmıştır. Süreç içerisindeki olumsuzluklar ve zorlukların öğrencilerde endişeye yol açtı̆̆ görülmüştür.

Anahtar Sözcükler: COVID-19, hemşirelik öğrencisi, hemşirelik eğitimi, uzaktan eğitim.

\section{Education of Nursing Students in the Covid-19 Pandemic Period: Distance Education Process and Its Effects}

\begin{abstract}
Aim: In this study, it was aimed to determine the distance education process and its effects on nursing students during the Covid-19 pandemic period.
\end{abstract}

Özgün Araştırma Makalesi (Original Research Article)

Geliş / Received: 13.08.2021 \& Kabul / Accepted: 08.12.2021

DOI: https://doi.org/10.38079/igusabder.982350

${ }^{*}$ Dr. Ögr. Üyesi, İstanbul Gelişim Üniversitesi, Sağlık Bilimleri Fakültesi, İstanbul, Türkiye,

E-posta: fkaraman@gelisim.edu.tr ORCID https://orcid.org/o000-0002-4177-9247

** Arş. Gör. İstanbul Gelişim Üniversitesi, Sağlık Bilimleri Fakültesi, İstanbul, Türkiye,

E-posta: sucakmak@gelisim.edu.tr ORCID https://orcid.org/o000-0001-8505-9586

*** Arş. Gör. İstanbul Gelişim Üniversitesi, Sağlık Bilimleri Fakültesi, İstanbul, Türkiye,

E-posta: anyerebakan@gelisim.edu.tr ORCID https://orcid.org/oooo-0003-4446-5785

ETIK BILLDIRIM: Çalışmanın yapılabilmesi için 25.02.2021 tarih ve 2021/o6/22 sayıh yazı ile İstanbul Gelişim Üniversitesi Etik Kurulu'ndan onay alınmıştır. 
Method: The sample of this descriptive study consisted of 243 students studying at the Nursing Department of the Faculty of Health Sciences. The data of the research were collected using the "Introductory Information Form" and "Information Form for the Distance Education Process". Descriptive statistical methods were used in the analysis of the data.

Results: $92.2 \%$ of the students participating in the research stated that they preferred the Nursing department willingly. $84.8 \%$ of the participant students stated that the distance education process negatively affected practical nursing education and $53.5 \%$ stated that it negatively affected theoretical nursing education. Although $68.7 \%$ of the students stated that the online course saves time, as they could do many other things; while $81.5 \%$ think that it is not enough to get practical courses remotely. As the rate of those who think that giving the theoretical courses remotely is sufficient is $57.2 \%$; it was determined that $63.4 \%$ of the students were concerned about the efficiency of the courses in the distance education system, and the rate of understanding the entire course content during the online course was 50.3\%. The rate of the students that had complaints such as eye problems and headaches due to their online course were $58 \%$.

Conclusion: Although distance education during the pandemic period has been seen as a great convenience in terms of time and space flexibility by nursing students; it has been determined that it causes learning difficulties in students, difficulty in adaptation in practice and clinical experiences, and negative effects on the development process of nursing skills. It has been observed that the negativities and difficulties in the process cause anxiety in students.

Keywords: COVID-19, nursing student, nursing education, distance education.

\section{Giriş}

Yeni Koronavirüs hastalığı (COVID-19), 2019 yılında keşfedilen bulaşıcı bir hastalık olup, Çin’in Wuhan kentinde ortaya çıkmış ve kısa bir süre içinde de tüm dünyaya yayılmıştır ${ }^{1-3}$.

COVID-19 küresel yayılımı nedeniyle önemli bir halk sağlığı sorunu olmuş ve birçok problemi de beraberinde getirmiştir. Eğitim sistemi de bu önemli sorunlardan biri haline gelmiştir ve pandemi süreci, dünyanın dört bir yanındaki okulların ve üniversitelerin yüz yüze öğretme-öğrenme faaliyetlerini çevrimiçi ve uzaktan öğrenmeye geçirmeye zorlamıştır4,5. Okulların ve üniversitelerin kapatılması, bu bulaşıcı hastalığın yayılmasını yavaşlatmak için kullanılan en yüksek profilli sosyal (fiziksel) uzaklaşma önlemlerinden biri olmuştur' ${ }^{6}$ Okullardan bazıları 2019-2020 eğitim-öğretim yılı bahar yarıyılını bir sonraki seneye aktarmayı seçerken, bazı okullar da uzaktan eğitimi destekleyen sistemleri tercih ederek eğitimi devam ettirmeye başlamıştır7.

Türkiye'de, koronavirüs hastalığının yayılmasını azaltmak ve eğitim-öğretimde yaşanan aksaklıkları ortadan kaldırmak için Yüksek Öğretim Kurumu (YÖK), 16 Mart 2020 tarihinden itibaren üniversitelerde eğitime 3 hafta ara verdiğini açıklamıştır ${ }^{8}$. Fakat salgın sürecinin belirsiz olması nedeniyle 26 Mart 2020 tarihinde YÖK tarafından 2019-2020 eğitim-öğretim yılı bahar yarıyılında yüz yüze ders yapılmayacağı duyurularak, uzaktan eğitim sistemi gündeme gelmiştir9.

Uzaktan eğitim sistemi, bu salgın sürecinde çok önemli bir rol üstlenmiştir. Uzaktan eğitim, üniversitelerin ve okulların kapatıldığı dönemlerde; süreci etkili yöneterek hem öğrencilerin öğrenimini kolaylaştırmak hem de öğrencilerin mezun olamama veya dönem kaybetme gibi mağduriyet yaşamasının engellenmesi adına hızlıca hayata geçirilmesi gereken önemli bir uygulama olarak karşımıza çıkmıştır ${ }^{10,11}$.

Uzaktan eğitim sistemi olumlu katkılarının yanı sıra pek çok problemi de beraberinde getirmiştir. Pandemi ile birlikte yüz yüze eğitimin zorunlu olarak iptal edilmesi, hemşirelik eğitimcilerini ve öğrencilerini alışık olmadığı pek çok zorluklarla karşı karşıya bırakmış ve özellikle uygulamalı 
hemşirelik eğitiminin durması hemşirelik eğitimini olumsuz etkilemiştir ${ }^{12,13}$. Klinik uygulamaların çok büyük önem taşıdığı hemşirelik eğitiminde uzaktan eğitim sürecinin etkisinin daha farklı olacağı düşünülmektedir. Bu bağlamda bu çalışmada COVID-19 pandemi döneminde hemşirelik öğrencilerinin uzaktan eğitim süreci ve etkilerinin belirlenmesi amaçlanmıştır.

\section{Yöntem}

\section{Araştırmanın Amacı}

Bu çalışma, COVID-19 pandemi döneminde hemşirelik öğrencilerinin uzaktan eğitim süreci ve etkilerinin belirlenmesi amacıyla tanımlayıcı olarak yapılmıştır.

\section{Araştırmanın Örneklemi, Yeri ve Zamanı}

Araştırma, bir vakıf üniversitenin hemşirelik bölümünde eğitim gören öğrencilerle, 1 Nisan-1 Mayıs 2021 tarihleri arasında yürütülmüştür. Araştırmanın evrenini üniversitenin sağlık bilimleri fakültesi hemşirelik bölümünde öğrenim gören 729 öğrenci oluşturmuştur. Araştırmada örneklem seçimine gidilmemiş olup, evrenin tümüne ulaşılması hedeflenmiştir. Araştırmaya katılmayı kabul eden ve veri toplama formlarını eksiksiz dolduran 243 hemşirelik öğrencisi ile araştırma tamamlanmıştır.

\section{Veri Toplama Araçları}

Araştırma verileri, araştırmacılar tarafından hazırlanmış olan "Tanıtıcı Bilgi Formu" ve uzaktan eğitimin etkinliğinin ve erişilebilirliğinin değerlendirildiği, araştırmacılar tarafından literatür doğrultusunda hazırlanan²,45,10,11 22 maddelik "Uzaktan Eğitim Sürecine Yönelik Bilgi Formu" kullanılarak online olarak elde edilmiştir.

\section{Verilerin Analizi}

İstatistiksel analizler SPSS paket programında yapılmış olup, analizlerde aritmetik ortalama, frekans ve yüzde değerleri kullanılmıştır.

\section{Etik Hususlar}

Çalışmanın yapılabilmesi için 25.02.2021 tarih ve 2021/06/22 sayılı yazı ile İstanbul Gelişim Üniversitesi Etik Kurulu'ndan onay alınmıştır. Online olarak çalışmaya katılmayı kabul eden her öğrenciye araştırmanın amacı hakkında bilgi verilmiş ve bilgilendirilmiş onam formu ile rıza alınmıştır.

\section{Bulgular}

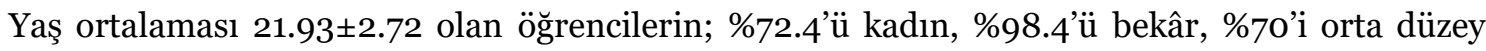
gelirde ve \%68.3’ü çekirdek aileye sahiptir. Katılımcıların \%35’i 1. sınıfta öğrenim görmektedir. Pandemi sürecinde katılımcıların çoğu ilde yaşadığını (\%54.7) ve ailesi ile birlikte kaldığını (\%79.8) belirtmişlerdir.

Öğrencilerin \%92.2'si hemşirelik bölümünü isteyerek seçtiğini, \%52.3’ü akademik durumunun orta seviyede olduğunu ifade etmiştir. Katılımcıların \%53.5’i uzaktan eğitim sürecinin teorik hemşirelik eğitimi üzerindeki etkisini ve \%84.8’i uzaktan eğitim sürecinin uygulamalı hemşirelik eğitimi üzerindeki etkisini olumsuz olarak algılamaktadır. Öğrencilerin \%66.7’sinin uzaktan eğitim sürecinde sınav sisteminin yeterliliği hakkındaki düşüncesinin olumlu olduğu saptanmıştır (Tablo 1). 
Hemşirelik öğrencilerinin uzaktan eğitim süreci hakkındaki görüşleri incelendiğinde; \%53.1’i üniversite yerine evde ders almanın hoşuna gitmediğini, \%56.4’ü çevrimiçi eğitim süresince kullanılan dijital teknoloji ile kendini güncellemekten memnun olduğunu, \%68.7'si çevrimiçi dersin zaman kazandırdığını, böylece diğer birçok işlerini yapabildiğini ve \%59.7'si çevrimiçi sınıfa katılabildiği ve aynı zamanda ailesiyle birlikte olduğu için mutlu olduğunu belirtmiştir. "Okulda pek çok kişiyle buluşmak zordu, çevrimiçi ders nedeniyle bir arada olmak daha kolay" ifadesine öğrencilerin \%55.1’i "hayır” yanıtını vermiştir. Öğrencilerden \%79'u “çevrimiçi ders, evden okula gitmediğim için seyahat maliyetimi düşürüyor" ve \%72.8’i “çevrimiçi ders, okula gitmediğim için kaza riskimi azaltıyor" ifadelerine "evet” yanıtını vermiştir.

Katılımcıların çoğu (\%81.5) uygulamaya dayalı derslerin uzaktan verilmesinin yeterli olmadığını düşünmektedir. Teorik derslerin ise uzaktan verilmesinin yeterli olduğunu düşünenlerin oranı ise \%57.2'dir. Öğrencilerin \%63.4'ü uzaktan eğitim sistemi ile derslerin verimliliği konusunda endişeli olduğunu, \%87.7'si çevrimiçi eğitim için evinde internet erişiminin olduğunu, \%84'ü çevrimiçi eğitim için kullanılan program hakkında tam bilgiye sahip (katılma, kaydetme, sesi kapatma-açma, ayrılma vb.) olduğunu ve \%50.3’ü çevrimiçi ders sırasında anlatılan dersin (içerik) tamamını anladığını belirtmiştir.

Öğrencilerin \%58.8’i “çevrimiçi dersimde elektrik sorunu yüzünden rahatsız oluyorum” ile \%51.5’i "çevrimiçi dersimde internet sorunu nedeniyle rahatsız oluyorum" ifadelerine "hayır" yanıtını vermiştir. Katılımcıların çoğunun çevrimiçi ders için ayrılan zamandan memnun olduğu (\%65.4), çevrimiçi ders sırasında öğretmeni ile iyi iletişim kurduğu (\%61.7) ve çevrimiçi dersi için dizüstü bilgisayar/bilgisayar kullandığı saptanmıştır. Öğrenciler "katılmak için herhangi bir sorun yaşamasam bile çevrimiçi sınıfıma katılmakla ilgilenmiyorum" sorusuna \%76.1 oran ile "hayır" yanıtını vermişlerdir. Katılımcıların \%77'si çevrimiçi sınıfına katılamadığı zamanlarda bile öğretmenlerden notlar/ders materyalleri aldığını, \%65’i çevrimiçi sınıfın soru/cevap oturumuyla sorularını netleştirdiğini ifade etmiştir. Öğrencilerin \%58’i çevrimiçi dersi nedeniyle göz sorunu/baş ağrısından muzdarip olduğunu ifade etmiştir (Tablo 2).

Tablo 1. Öğrencilerin bireysel özelliklerine göre dağılımı (n=243)

\begin{tabular}{|l|l|l|l|}
\hline & Bireysel Özellikler & $\mathbf{n}$ & $\mathbf{\%}$ \\
\hline \multirow{2}{*}{ Medensiyet } & Erkek & 67 & 27.6 \\
& Kadın & 176 & 72.4 \\
\hline \multirow{3}{*}{ Sinıf } & Bekâr & 239 & 98.4 \\
& Evli & 4 & 1.6 \\
\hline \multirow{3}{*}{ Aile Tipi } & 1. Sinıf & 85 & 35.0 \\
& 2. Sinıf & 39 & 16.0 \\
& 3. Sinıf & 60 & 24.7 \\
Gelir Durumum & 4. Sinıf & 59 & 24.3 \\
& Çekirdek aile & 166 & 68.3 \\
& Geniş aile & 65 & 26.7 \\
Pandemi Sürecinde Yaşadı̆̆ Yer & Parçalanmış aile & 12 & 5.0 \\
\hline & İyi & 41 & 16.9 \\
& Orta & 170 & 70.0 \\
& Kötü & 32 & 13.1 \\
\hline
\end{tabular}




\begin{tabular}{|c|c|c|c|}
\hline Pandemi Sürecinde Kiminle Kaldığı & $\begin{array}{l}\text { Ailemin yanında } \\
\text { Yurtta } \\
\text { Arkadaşlarımla } \\
\text { birlikte evde } \\
\text { Tek başıma evde }\end{array}$ & $\begin{array}{l}194 \\
2 \\
25 \\
22\end{array}$ & $\begin{array}{l}79.8 \\
0.8 \\
10.3 \\
9.1\end{array}$ \\
\hline Hemşirelik Bölümünü İsteyerek Seçme Durumu & $\begin{array}{l}\text { Evet } \\
\text { Hayır }\end{array}$ & $\begin{array}{l}224 \\
19\end{array}$ & $\begin{array}{l}92.2 \\
7.8\end{array}$ \\
\hline Akademik Durumu & $\begin{array}{l}\text { İyi } \\
\text { Orta } \\
\text { Kötü }\end{array}$ & $\begin{array}{l}106 \\
127 \\
10\end{array}$ & $\begin{array}{l}43.6 \\
52.3 \\
4.1\end{array}$ \\
\hline Yakın Çevrede Covid-19 Tanısı Alma Durumu & $\begin{array}{l}\text { Evet } \\
\text { Hayır }\end{array}$ & $\begin{array}{l}154 \\
89\end{array}$ & $\begin{array}{l}63.4 \\
36.6\end{array}$ \\
\hline $\begin{array}{l}\text { Uzaktan Eğitim Sürecinin Teorik Hemşirelik Eğitimi } \\
\text { Üzerindeki Etkisini Algılama Durumu }\end{array}$ & $\begin{array}{l}\text { Olumlu } \\
\text { Olumsuz }\end{array}$ & $\begin{array}{l}113 \\
130\end{array}$ & $\begin{array}{l}46.5 \\
53.5\end{array}$ \\
\hline $\begin{array}{l}\text { Uzaktan Eğitim Sürecinin Uygulamalı Hemşirelik } \\
\text { Eğitimi Üzerindeki Etkisini Algılama Durumu }\end{array}$ & $\begin{array}{l}\text { Olumlu } \\
\text { Olumsuz }\end{array}$ & $\begin{array}{l}36 \\
206 \\
\end{array}$ & $\begin{array}{l}15.2 \\
84.8\end{array}$ \\
\hline $\begin{array}{l}\text { Uzaktan Eğitim Sürecinde Sınav Sisteminin Yeterliliği } \\
\text { Hakkındaki Düşüncesi }\end{array}$ & $\begin{array}{l}\text { Olumlu } \\
\text { Olumsuz }\end{array}$ & $\begin{array}{l}162 \\
81\end{array}$ & $\begin{array}{l}66.7 \\
33.3\end{array}$ \\
\hline
\end{tabular}

Tablo 2. Hemşirelik Öğrencilerinin Uzaktan Eğitimi Süreci Hakkındaki Görüşleri (n=243)

\begin{tabular}{|c|c|c|c|c|}
\hline & $\begin{array}{l}\text { Evet } \\
\text { n (\%) }\end{array}$ & $\begin{array}{l}\text { Hayır } \\
\text { n (\%) }\end{array}$ & & yorum \\
\hline Okuldan çok evde ders almak daha hoşuma gidiyor. & $77(31.7)$ & $\begin{array}{l}129 \\
(53.1)\end{array}$ & 37 & $(15.2)$ \\
\hline $\begin{array}{l}\text { Okulda pek çok kişiyle buluşmak zordu, çevrimiçi ders } \\
\text { nedeniyle bir arada olmak daha kolay. }\end{array}$ & $\begin{array}{l}67 \\
(27.6) \\
\end{array}$ & $\begin{array}{l}134 \\
(55.1) \\
\end{array}$ & 42 & $(17 \cdot 3)$ \\
\hline $\begin{array}{l}\text { Çevrimiçi eğitim süresince kullanılan dijital teknoloji ile } \\
\text { kendimi güncellemekten memnunum. }\end{array}$ & $\begin{array}{l}137 \\
(56.4)\end{array}$ & $\begin{array}{l}71 \\
(29.2)\end{array}$ & 35 & $(14.4)$ \\
\hline $\begin{array}{l}\text { Çevrimiçi ders zaman kazandırıyor, böylece diğer birçok işimi } \\
\text { yapabiliyorum. }\end{array}$ & $\begin{array}{l}167 \\
(68.7)\end{array}$ & $\begin{array}{l}60 \\
(24.7)\end{array}$ & 16 & $(6.6)$ \\
\hline $\begin{array}{l}\text { Çevrimiçi sınıfa katılabildiğim ve aynı zamanda ailemle birlikte } \\
\text { olduğum için mutluyum. }\end{array}$ & $\begin{array}{l}145 \\
(59.7)\end{array}$ & $61(25.1)$ & 37 & $(15.2)$ \\
\hline $\begin{array}{l}\text { Çevrimiçi ders, evden okula gitmediğim için seyahat maliyetimi } \\
\text { düşürüyor. }\end{array}$ & $\begin{array}{l}192 \\
(79.0)\end{array}$ & $37(15.2)$ & 14 & $(5.8)$ \\
\hline Çevrimiçi ders, okula gitmediğim için kaza riskimi azaltıyor. & $\begin{array}{l}177 \\
(72.9)\end{array}$ & $\begin{array}{l}40 \\
(16.4)\end{array}$ & 26 & $(10.7)$ \\
\hline $\begin{array}{l}\text { Uygulamaya dayalı derslerin uzaktan verilmesinin yeterli } \\
\text { olmadığını düşünüyorum. }\end{array}$ & $\begin{array}{l}198 \\
(81.5)\end{array}$ & $27(11.1)$ & 18 & $(7.4)$ \\
\hline $\begin{array}{l}\text { Teorik derslerin uzaktan verilmesinin yeterli olduğunu } \\
\text { düşünüyorum. }\end{array}$ & $\begin{array}{l}139 \\
(57.2)\end{array}$ & $\begin{array}{l}83 \\
(34.2)\end{array}$ & 21 & $(8.6)$ \\
\hline $\begin{array}{l}\text { Uzaktan eğitim sistemi ile derslerin verimliliği konusunda } \\
\text { endişeliyim. }\end{array}$ & $\begin{array}{l}154 \\
(63.4)\end{array}$ & $\begin{array}{l}50 \\
(20.6)\end{array}$ & 39 & $(16.0)$ \\
\hline Çevrimiçi eğitimim için evimde internet erişimim var. & $\begin{array}{l}213 \\
(87 \cdot 7)\end{array}$ & $27(11.1)$ & 3 & $(1.2)$ \\
\hline $\begin{array}{l}\text { Çevrimiçi dersimde elektrik sorunu yüzünden rahatsız } \\
\text { oluyorum. }\end{array}$ & $78(32.1)$ & $\begin{array}{l}143 \\
(58.8)\end{array}$ & 22 & (9.1) \\
\hline $\begin{array}{l}\text { Çevrimiçi dersimde internet sorunu nedeniyle rahatsız } \\
\text { oluyorum. }\end{array}$ & $\begin{array}{l}99 \\
(40.7)\end{array}$ & $\begin{array}{l}125 \\
(51.5)\end{array}$ & 19 & 7.8) \\
\hline
\end{tabular}




\begin{tabular}{|l|l|l|lr|}
\hline $\begin{array}{l}\text { Çevrimiçi eğitim için kullanılan program hakkında tam bilgiye } \\
\text { sahibim (katılma, kaydetme, sesi kapatma-açma, ayrılma vb.). }\end{array}$ & $\begin{array}{l}204 \\
(84.0)\end{array}$ & $\begin{array}{l}25 \\
(10.2)\end{array}$ & 14 & $(5.8)$ \\
\hline $\begin{array}{l}\text { Çevrimiçi ders sırasında anlatılan dersin (içerik) tamamını } \\
\text { anlıyorum. }\end{array}$ & $\begin{array}{l}122 \\
(50.2)\end{array}$ & $\begin{array}{l}82 \\
(33.8)\end{array}$ & 39 & $(16.0)$ \\
\hline Çevrimiçi ders için ayrılan zamandan memnunum. & $\begin{array}{l}159 \\
(65.4)\end{array}$ & $\begin{array}{l}68 \\
(28.0)\end{array}$ & 16 & $(6.6)$ \\
\hline $\begin{array}{l}\text { Çevrimiçi dersim için dizüstü bilgisayar / bilgisayar } \\
\text { kullanıyorum. }\end{array}$ & $\begin{array}{l}185 \\
(76.2)\end{array}$ & $\begin{array}{l}56 \\
(23.0)\end{array}$ & 2 & $(0.8)$ \\
\hline $\begin{array}{l}\text { Çevrimiçi dersim sırasında öğretmenimle iyi iletişim } \\
\text { kurabiliyorum. }\end{array}$ & $\begin{array}{l}150 \\
(61.7)\end{array}$ & $\begin{array}{l}56 \\
(23.0)\end{array}$ & 37 & $(15.3)$ \\
\hline $\begin{array}{l}\text { Katılmak için herhangi bir sorun yaşamasam bile çevrimiçi } \\
\text { sinıfıma katılmakla ilgilenmiyorum. }\end{array}$ & $\begin{array}{l}36 \\
(14.8)\end{array}$ & $\begin{array}{l}185 \\
(76.1)\end{array}$ & 22 & $(9.1)$ \\
\hline $\begin{array}{l}\text { Çevrimiçi sınıfıma katılamadığım zamanlarda bile } \\
\text { ŏğretmenlerden notlar / ders materyalleri alıyorum. }\end{array}$ & $\begin{array}{l}187 \\
(77.0)\end{array}$ & $\begin{array}{l}38 \\
(15.6)\end{array}$ & 18 & $(7.4)$ \\
\hline $\begin{array}{l}\text { Çevrimiçi sınıfın soru / cevap oturumuyla sorularımı } \\
\text { netleştiriyorum. }\end{array}$ & $\begin{array}{l}158 \\
(65.0)\end{array}$ & $\begin{array}{l}50 \\
(20.6)\end{array}$ & 35 & $(14.4)$ \\
\hline $\begin{array}{l}\text { Çevrimiçi dersim nedeniyle göz sorunu / baş ağrısından } \\
\text { muzdarip olduğumu hissediyorum. }\end{array}$ & $\begin{array}{l}141 \\
(58.0)\end{array}$ & $\begin{array}{l}84 \\
(34.6)\end{array}$ & 18 & $(7.4)$ \\
\hline
\end{tabular}

\section{Tartışma}

COVID-19 pandemisi, teorik ve uygulamalı hemşirelik eğitimi üzerinde zorunlu değişikliklere yol açmış ve çevrimiçi eğitim, eğitimin sürdürülmesi için tek seçenek olarak karşımıza çıkmıştır ${ }^{14}$. Çalışmaya katılan öğrenciler, uzaktan eğitim sürecinin teorik hemşirelik eğitimi üzerindeki etkisini \%53.5 oranında olumsuz olarak algılarken, öğrencilerin \%63.4'ü uzaktan eğitim sistemi ile yürütülen derslerin verimliliği konusunda endişe duymaktadır. Oducado ve Estoque (2021) hemşirelik bölümü öğrencilerinde yaptığı çalışmada öğrencilerin çevrimiçi öğrenme memnuniyet oranlarının orta düzey (\%46.3) olduğunu saptamıştır. Aynı çalışmada öğrencilerin büyük çoğunluğu (\%91.6) çevrimiçi öğrenmenin stresli olduğunu düşünmektedir5. Bu çalışmada öğrencilerin yarısına yakını çevrimiçi anlatılan ders içeriğinin tamamını anlayamamıştır. Çevrimiçi yürütülen teorik derslerdeki düşük başarının nedenleri araştırıldı̆̆ında birçok faktör karşımıza çıkmaktadır.

Öğrenciler alıştıkları kalabalık sınıf ortamından bir anda uzaklaşıp teknolojik cihazlara uyum sağlamaya çalışmışlardır. Bu süreçte her öğrencinin adaptasyon süresi aynı olmamıştır ${ }^{15}$. İnternet, bilgisayar ve telefon gibi teknolojik imkânlar açısından sınırlı olan öğrencilerde derslere düzenli katılım sağlanamamıştır. Sokağa çıkma yasağı ev halkının bir arada olmasını sağlarken birçok öğrenci, eğitmenler ve akranlarıyla etkileşim kurmak için ayrı bir oda bulamamıştır.

Öğrencilerin ev içerisinde akran müdahalesi ile karşılaşması ve teknolojik imkânları paylaşmak zorunda kalması öğrencilerin dikkatini dağıtan önemli bir faktör olmuştur. Çevrimiçi derslerde öğrencilerin elektrik ve internet nedeniyle de sorun yaşadığı görülmüştür ${ }^{11}$.

Çevrimiçi derslerde öğrenci merkezli eğitim yönteminin daha az kullanılmış olması, öğrencilerin eğitmenler ile yeterince etkileşime geçememesi ve canlı olmayan video kaydı ile yürütülen derslerde ise soru soramamaları öğrencilerin ders içeriğini anlama düzeyini olumsuz etkilemiştir ${ }^{16}$. Bu çalışmada öğrencilerin \%61.7'si çevrimiçi ders sırasında öğretmen ile iyi iletişim kurabildiğini ifade ederken Tümen Akyıldız’n (2020) çalışmasında katılımcıların tamamına 
yakını web tabanlı derslerde öğretim elemanları ile kendi aralarındaki etkileşim eksikliğinden kaynaklanan çeşitli sorunlar yaşadıklarını ifade etmiştir ${ }^{17}$.

Öğrencilerin çevrimiçi eğitimde en olumlu buldukları özellik "zaman ve mekân esnekliğgi" sağlamış olmasıdır. Öğrenciler kendi programlarına göre çalışabilmeleri, erken kalkıp okula gitmek zorunda olmamaları, istenilen her yerde ve zamanda videoların izlenebilmesi, ders dokümanlarının incelenebilmesi öğrencilerin çevrimiçi eğitimden memnun olmalarını sağlamıştır ${ }^{17}$. Nepal'de yapılan bir çalışmada bu verilerin aksine hemşirelik öğrencilerinin yarısından fazlasının okuldan ziyade evde ders almaktan hoşlanmadığı ve yüz yüze eğitimde daha fazla insanla bir araya gelebildiği belirtilmiştir. Fakat yine aynı çalışmada bizim verilerimize paralel olarak öğrenciler, dersleri dijital teknoloji ile takip etmekten memnun olduğunu, çevrimiçi derslerin vakit kazandırdığını, kalan vakitlerinde diğer işlerini yapabildikleri ve aileleriyle daha fazla vakit geçirebildiklerini ifade etmişlerdir ${ }^{11}$. Öğrenciler, çevrimiçi eğitimde ders içeriğinin özet şekliyle paylaşılması, daha fazla bilgi edinmek için geleneksel yöntemlere oranla öğrenciyi daha fazla araştırma yapmaya teşvik ettiğini belirtmiştir ${ }^{17}$. Bu çalışmada üniversite öğrencileri, çevrimiçi derslerin, seyahat maliyetini (\%79) ve kaza riskini (\%72.8) düşürdüğünü ifade etmiştir. Subedi ve arkadaşları (2020) öğrencilerin, evde ders almayı istemeseler (\%54.8’i) de çevrimiçi derslerin zamandan tasarruf sağladığını (\%66.3), seyahat maliyetlerini (\%71.5) ve kaza riskini (\%71.6) düşürdüğünü belirtmişlerdir ${ }^{11}$.

Pandemi döneminde uygulamalı hemşirelik eğitimi, sanal ortam ve çevrimiçi simülasyon gibi çeşitli uygulamalar ile yürütülmüştür. Araştırmaya katılan öğrenciler, uzaktan eğitim sürecinin uygulamalı hemşirelik eğitimi üzerindeki etkisini \%84.8 oranında olumsuz olarak algılarken \%81.5 oranında uygulamaya dayalı derslerin uzaktan verilmesinin yeterli olmadığını düşünmektedir. Michel ve arkadaşlarının (2021) hemşirelik öğrencilerinde uzaktan eğitim uygulamalarının etkisini araştırdığı çalışmada, öğrencilerin büyük bir kısmı eğitim gördüğü sırada klinik uygulama yapamadığ i için endişe duymaktadır ${ }^{15}$. Hasta ile etkileşime geçemeyen ve hemşirelik uygulama becerilerini geliştiremeyen öğrencilerin mezun olduktan sonra iş bulmalarının zorlaşacağı düşünülmektedir.

Pandemi sürecinde hemşirelik öğrencilerinin sınav notları, dersin içeriğine göre değişiklik göstererek çevrimiçi sınavlar, performans ödevleri, vaka tartışması ve bakım planları ile

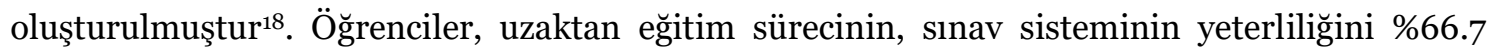
oranında olumlu etkilediğini belirtmişlerdir. Tümen Akyıldız’ın (2020) çalışmasında öğrenciler, sınava girme konusunda bazı sorunlar yaşasalar da geleneksel sınavlara oranla daha yüksek not aldıklarını ve cevapları kontrol etme imkânına sahip olduklarını belirtmişlerdir. Öğrencilerin akademik performansı COVID-19 pandemisinden önemli ölçüde etkilenmiş olup öğrencilerin büyük bir çoğunluğu notların adil sonuçlanmadığını ifade etmiştir5.

Araştırma sonucunda öğrencilerin yarısı çevrimiçi dersler nedeniyle göz problemi ve baş ağrısı deneyimlemiştir. Çevrimiçi eğitim nedeniyle teknolojik cihazların kullanımı artış göstererek çeşitli göz ${ }^{19,20}$ ve baş ağrısı ${ }^{21}$ gibi sorunları gündeme getirmiştir.

\section{Sonuç ve Öneriler}

$\mathrm{Bu}$ araştırmanın bulguları, uzaktan öğretime geçişin, öğrencilerin genel refahını olumsuz etkilediğini, öğrenmede zorluklar yarattığını, özellikle de uygulamalı hemşirelik eğitimi üzerinde daha fazla olumsuz sonuçlara neden olarak öğrencilerin klinik deneyim edinme ve hemşirelik becerilerini geliştirme konusunda yaşadığı zorlukları vurgulamıştır. Tüm bu zorlukların öğrencilerde endişeye yol açtı̆̆ı görülmüştür. Öğrencilerin çevrimiçi eğitimden yeterince 
memnun olmadığı ancak çevrimiçi eğitimin öğrencilere zaman ve mekân esnekliği sağladığı için kolaylık oluşturduğu görülmüştür. Çevrimiçi eğitim, COVID-19 salgını sırasında virüs bulaşmasını azaltmak için değerli bir çözüm olsa da, öğrencilerin öğrenme ihtiyaçlarını karşlamak için mevcut öğrenme ortamında kullanılan yöntemleri iyileştirmek için önlemler alınmalıdır. Uzaktan eğitimde yaşanan sosyal etkileşim eksikliği dersin verimliliğini etkileyen büyük bir zorluktur ve eğitmenlerin sosyal etkileşimleri geliştiren öğrenme yöntemlerini en verimli şekilde kullanması gerekmektedir. Öğrenciler için tamamlayıcı e-kaynakların geliştirilmesi, müfredat yeniliği ve dönüşümü, onların klinik veya uygulamalı derslere daha fazla odaklanmalarını sağlayacak ve çevrimiçi derslerin etkinliğini artırarak öğrenciler arasında memnuniyet düzeylerinin iyileşmesini sağlayacaktır.

Çıkar Çatışması: Bu çalışmada herhangi bir çıkar çatışması bulunmamaktadır.

Etik Kurul Onayı: Çalışmanın yapılabilmesi için 25.02.2021 tarih ve 2021/o6/22 sayılı yazı ile İstanbul Gelişim Üniversitesi Etik Kurulu'ndan onay alınmıştır. Online olarak çalışmaya katılmayı kabul eden her öğrenciye araştırmanın amacı hakkında bilgi verilmiş ve bilgilendirilmiş onam formu ile rıza alınmıştır.

\section{KAYNAKLAR}

1. Huang C, Wang Y, Li X, et al. Clinical features of patients infected with 2019 novel coronavirus in Wuhan, China. The Lancet. 2020;395(10223):497-506. doi:10.1016/So1406736(20)30183-5.

2. Kürtüncü M, Kurt A. Covid-19 pandemisi döneminde hemşirelik öğrencilerinin uzaktan eğitim konusunda yaşadıkları sorunlar. Avrasya Sosyal ve Ekonomi Araştırmaları Dergisi. 2020;7(5):66-77. Erişim adresi: https://dergipark.org.tr/tr/download/article-file/1128112.

3. She J, Jiang J, Ye L, Hu L, Bai C, Song Y. 2019 novel coronavirus of pneumonia in Wuhan, China: emerging attack and management strategies. Clinical and Translational Medicine. 2020;9(1):1-7. doi:http://doi.org/10.1186/s40169-020-00271-z.

4. Masha'al D, Rababa M, Shahrour G. Distance learning-related stress among undergraduate nursing students during the COVID-19 pandemic. Journal of Nursing Education. 2020;59(12): 666-674. doi:10.3928/01484834-20201118-03.

5. Oducado RMF, Estoque HV. Online Learning in nursing education during the COVID-19 pandemic: stress, satisfaction, and academic performance. Journal of Nursing Practice. 2021;4(2):143-153. doi:10.30994/jnp.v4i2.128.

6. Bayham J, Fenichel EP. Impact of school closures for COVID-19 on the US health-care workforce and net mortality: A modelling study. Lancet Public Heal. 2020;5(5):271-278. doi: $10.1016 /$ S2468-2667(20)30082-7.

7. Domenico LD, Pullano G, Coletti P, Hens N, Colizza V. Expected impact of school closure and telework to mitigate COVID-19 epidemic in France. Epicx Lab. http://www.epicxlab.com/uploads/9/6/9/4/9694133/inserm covid-19-school-closure-frenchregions 20200313.pdf. Yayınlanma tarihi 14 Mart 2020. Erişim tarihi 4 Haziran 2021. 
8. Yüksek Öğretim Kurumu (YÖK). Basın Açılaması. YÖK. https://www.yok.gov.tr/Sayfalar/Haberler/2020/YKS\%20Ertelenmesi\%20Bas\%C4\%B1n\% 20A\%C3\%A7\%C4\%B1klamas\%C4\%B1.aspx Yayınlanma tarihi 26 Mart 2020. Erişim tarihi 20 Mayıs 2021.

9. Yüksek Öğretim Kurumu (YÖK). Koronavirüs (Covid-19) Bilgilendirme Notu: 1. YÖK.https://www.yok.gov.tr/Sayfalar/Haberler/2020/coronavirus bilgilendirme_1.aspx Yayınlanma tarihi 13 Mart 2020. Erişim tarihi 20 Mayıs 2021.

10. Almaia MA, Al-Khasawneh A, Althunibat A. Exploring the critical challenges and factors influencing the e-learning system usage during COVID-19 pandemic. Educ Inf Technol. 2020;5(3):1-20. doi: 10.1007/s10639-020-10219-y.

11. Subedi S, Nayaju S, Subedi S, Shah SK, Shah JM. Impact of e-learning during COVID-19 pandemic among nursing students and teachers of Nepal. International Journal of Science and Healthcare Research. 2020;5(3):68-76.

12. Aggarwal G, Aggarwal S, Robles J, Depasquale JR, Auseon A. Medical education focus in published articles related to COVID-19. Eur Rev Med Pharmacol Sci. 2020;24(14):79057907. doi: 10.26355/ eurrev_202007_22297.

13. Şanlı D, Uyanık G, Avdal EÜ. COVID-19 pandemi sürecinde dünyada hemşirelik eğitimi. İzmir Kâtip Çelebi Üniversitesi Sağllk Bilimleri Fakültesi Dergisi. 2021;6(1):55-63.

14. Dutta S, Ambwani S, Lal H, et al. The satisfaction level of undergraduate medical and nursing students regarding distant preclinical and clinical teaching amidst COVID-19 across India. Advances in Medical Education and Practice. 2021;12:113-122. doi: 10.2147/AMEP.S290142.

15. Michel A, Ryan N, Mattheus D, et al. Undergraduate nursing students' perceptions on nursing education during the 2020 COVID-19 pandemic: A national sample. 2021. Nursing Outlook. 2021;00:1-10. https://doi.org/10.1016/j.outlook.2021.05.004

16. Faize AF, Nawaz M. Evaluation and improvement of students' satisfaction in online learning during COVID-19. Open Praxis. 2020;12(4):495-507. doi:10.5944/openpraxis.12.4.1153.

17. Tümen Akyldız S. College students' views on the pandemic distance education: A focus group discussion. International Journal of Technology in Education and Science. 2020;4(4):322-334.

18. Mucuk S, Ceyhan Ö, Tekinsoy Kartın P. COVID-19 pandemi sürecinde uzaktan hemşirelik eğitimi: ulusal deneyim. İzmir Katip Çelebi Üniversitesi Sağllk Bilimleri Fakültesi Dergisi. 2021;6(1):33-36.

19. Kim H, Kim SJ. Management of eye and vision symptoms caused by online learning among college students during COVID-19 Pandemic. J Korean Ophthalmic Opt Soc. 2021;26(1):7380. doi:10.14479/jkoos.2021.26.1.73.

20. Mohan A, Sen P, Shah C, Jain E, Jain S. Prevalence and risk factor assessment of digital eye strain among children using online e-learning during the COVID-19 pandemic: Digital eye strain among kids (DESK study-1). Indian Journal of Ophthalmology. 2021;69(1):140-144. doi: 10.4103/ijo.IJO_2535_20. 
21. Realyvásquez Vargas A, Maldonado-Macías AA, Arredondo-Soto KC, Baez-Lopez Y, Carrillo Gutiérrez T, Hernández-Escobedo G. The impact of environmental factors on academic performance of university students taking online classes during the COVID-19 Pandemic in Mexico. Sustainability. 2020;12(21):9194. doi:10.3390/su12219194. 